\title{
From public health genomics to precision public health: a 20-year journey
}

\author{
Muin J. Khoury, MD, $\mathrm{PhD}^{1}$, M. Scott Bowen, $\mathrm{MPH}^{1}$, Mindy Clyne, MS ${ }^{2}, \mathrm{~W}$. David Dotson, $\mathrm{PhD}^{1}$, \\ Marta L. Gwinn, MD, MPH ${ }^{3}$, Ridgely Fisk Green, $\mathrm{PhD}^{1}$, Katherine Kolor, PhD ${ }^{1}$, Juan L. Rodriguez, $\mathrm{PhD}^{4}$, \\ Anja Wulf ${ }^{1}$ and Wei $\mathrm{Yu}, \mathrm{PhD}^{1}$
}

In this paper, we review the evolution of the field of public health genomics in the United States in the past two decades. Public health genomics focuses on effective and responsible translation of genomic science into population health benefits. We discuss the relationship of the field to the core public health functions and essential services, review its evidentiary foundation, and provide examples of current US public health priorities and applications. We cite examples of publications to illustrate how Genetics in Medicine reflected the evolution of the field. We also reflect on how public-health genomics is contributing to the emergence of "precision public health" with near-term opportunities offered by the US Precision Medicine (AllofUs) Initiative.

Genet Med advance online publication 14 December 2017

Key Words: genomics; precision medicine; precision public health; public health

responsible translation of genomic research into population health benefits. ${ }^{1}$ Over the past two decades, the Centers for Disease Control and Prevention (CDC) and many other groups have developed and implemented public health genomics in the United States and globally. Examples of CDC initiatives for integrating genomics into public health are shown in Table 1.

Until recently, the role of public health in genomics has not been well defined. The mission of public health is to improve health on a population scale, and its unit of intervention is the

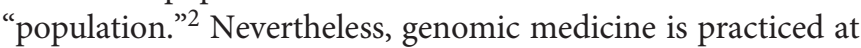
multiple levels of intervention including patient-provider interactions, health-care organizations, families, communities, and state and federal policies and programs. ${ }^{3}$ Also, as the use of genomics is introduced into disease prevention and health promotion, and with the continued growth of direct-toconsumer genetic testing, public health will be increasingly providing health information and education to empower consumers to make informed decisions about health. Finally, public health is concerned with the most vulnerable segments of the population, and will continue to play a major role in addressing health disparities in the implementation of genomics in practice.

\section{GENOMICS AND CORE PUBLIC HEALTH FUNC- TIONS AND SERVICES}

(e.g., newborn screening and maternal and child health programs), the field has evolved markedly in the past 20 years. Public health genomics is concerned with the effective and
In the United States, the contributions of genomics have been integrated into the core public health functions of assessment,

${ }^{1}$ Office of Public Health Genomics, Centers for Disease Control and Prevention, Atlanta, Georgia, USA; ${ }^{2}$ Division of Cancer Control and Population Sciences, National Cancer Institute, Rockville, Maryland, USA; ${ }^{3}$ Office of Advanced Molecular Detection, National Center for Emerging and Zoonotic Infectious Diseases, Centers for Disease Control and Prevention, Atlanta, Georgia, USA; ${ }^{4}$ Division of Cancer Prevention and Control, National Center for Chronic Disease Prevention and Health Promotion, Centers for Disease Control and Prevention, Atlanta, Georgia, USA. Correspondence: Muin j. Khoury (muk1@cdc.gov) 
Table 1 A selected timeline of public health genomics activities at the CDC, 1997-2017

\begin{tabular}{|c|c|c|}
\hline Year & Activity & Purpose/output \\
\hline 1997 & Creation of Office of Public Health Genomics & To help integrate genomics into public health policy research and programs \\
\hline 2000 & $\begin{array}{l}\text { First of three books on genomics and public health } \\
\text { published }\end{array}$ & $\begin{array}{l}\text { Raised awareness of a new field and contributed to training public health } \\
\text { professionals }{ }^{1}\end{array}$ \\
\hline 2001 & Human Genome Epidemiology Network & $\begin{array}{l}\text { Established a scientific foundation to synthesize information on gene-disease } \\
\text { associations; this led to development of an online curated knowledge base, the } \\
\text { Human Genome Epidemiology Navigator }\end{array}$ \\
\hline 2001 & Genomic competencies for public health workforce & $\begin{array}{l}\text { Established a practice foundation for the new field in different domains of } \\
\text { public health } 62\end{array}$ \\
\hline 2001 & Centers for Genomics and Public Health & $\begin{array}{l}\text { Established a focus of knowledge and information dissemination in schools of } \\
\text { public health } \\
63\end{array}$ \\
\hline 2002 & Family Health History Initiative & $\begin{array}{l}\text { Created tools and assessed how family history can be used to promote health } \\
\text { and prevent chronic diseases }{ }^{64}\end{array}$ \\
\hline 2004 & EGAPP Working Group & $\begin{array}{l}\text { Established an evidence-based independent process to review genomic tests for } \\
\text { practice and prevention }{ }^{66}\end{array}$ \\
\hline 2006 & Global public health genomics & Established an international collaboration in public health genomics ${ }^{67}$ \\
\hline 2009 & Recommendations on direct-to-consumer genetic tests & $\begin{array}{l}\text { Established a scientific foundation and research agenda for using personal } \\
\text { genomic tests to improve health }\end{array}$ \\
\hline 2010 & National conferences & $\begin{array}{l}\text { Conducted four national conferences }(1998,1999,2000,2010) \text { on genomics } \\
\text { and public health to share best practices and present information and findings } \\
\text { from programs } 69\end{array}$ \\
\hline 2011 & State cancer genomics programs & Established model state programs to reduce the burden of hereditary cancers ${ }^{70}$ \\
\hline 2016 & Precision Public Health & $\begin{array}{l}\text { Raised awareness about next-generation public health use tools of information } \\
\text { technology, genomics, and precision medicine in public health surveillance and } \\
\text { interventions }{ }^{54}\end{array}$ \\
\hline 2017 & $\begin{array}{l}\text { Current evidence base for implementing genomic } \\
\text { medicine }\end{array}$ & $\begin{array}{l}\text { Published two systematic reviews on the state of scientific evidence for large- } \\
\text { scale implementation of genomic medicine }{ }^{74,75}\end{array}$ \\
\hline
\end{tabular}

ACCE, analytical validity, clinical validity, clinical utility, and ethical, legal, and social issues; CDC, Centers for Disease Control and Prevention; EGAPP, Evaluation of Genomic Applications in Practice and Prevention; FH, familial hypercholesterolemia; HBOC, hereditary breast and ovarian cancer.

policy development, and assurance. These three functions were first discussed by the Institute of Medicine in $1988^{4}$ and have since been elaborated on to encompass 10 essential services. ${ }^{5}$ Table 2 shows the definitions and applications of the three essential public health functions as they relate to genomics, along with priorities for public health action. ${ }^{6,7}$ Over the past 20 years, GIM has published many articles on genomic activities that support these functions. Table 2 lists a few examples of Journal publications in each category.

\section{Policy development}

In its 20-year journey, GIM has published methods for evidence synthesis and recommendations for action (e.g., refs. $\left.{ }^{8,9}\right)$. One example of a public health guideline policy development group is the Advisory Committee on Heritable Disorders of Newborn and Children, an independent panel that provides evidence-based recommendations to the Secretary of the US Department of Health and Human Services on disorders to be included in the newborn screening 
Table 2 Contributions of public health to genomic medicine: examples from publications in Genetics in Medicine Public health functions/priorities Examples of articles in Genetics in Medicine

\author{
Function 1: Policy development \\ The formulation of standards and guidelines, in \\ collaboration with stakeholders, which promote \\ the appropriate use of genetic information and \\ the effectiveness, accessibility, and quality of \\ genetic tests and services. \\ Priorities \\ Conducting and sponsoring knowledge synthesis, \\ policy analysis, and recommendations on use and \\ impact of genomic information on populations
}

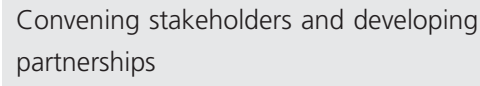

\section{Function 2: Assurance}

Assuring that genetic information is used appropriately and that genetic tests and services are used based on agreed-upon goals for effectiveness, accessibility, and quality.

\section{Priorities}

Use multilevel interventions (education, programs, influencing policy and practice, and addressing disparities)

\section{Function 3: Assessment}

The regular systematic collection, assembly, analysis, and dissemination of information including human genome epidemiologic information, on the health of the community

Priorities

Epidemiologic studies, behavioral and social sciences, communication sciences, health services research, economic evaluations, comparative effectiveness research, training and education
Advisory Committee on Heritable Disorders; ${ }^{8}$ Evaluation of Genomic Applications in Practice and Prevention; ${ }^{9}$ Evidence synthesis and guideline development in genomic medicine: current status and future prospects; ${ }^{76} \mathrm{~A}$ standardized, evidence-based protocol to assess clinical actionability of genetic disorders associated with genomic variation ${ }^{77}$

Implementing screening for Lynch syndrome among patients with newly diagnosed colorectal cancer: summary of a public health/clinical collaborative meeting; ${ }^{10}$ Stakeholder assessment of the evidence for cancer genomic tests ${ }^{11}$ 
bringing $B R C A 1 / 2$ genetic screening to the US Ashkenazi Jewish population. ${ }^{13} \mathrm{~A}$ third described the use of electronic health record interventions at the point of care to improve documentation of care processes. ${ }^{14}$

\section{Assessment \\ Assessment draws on multidisciplinary public health sciences such as epidemiologic studies; behavioral, communication, and social sciences; economic analysis, health services research; comparative-effectiveness studies; and public health surveillance of health impact and disparities. Table 1 lists examples of publications on public health assessment of genetics and family history using approaches including health-services research, ${ }^{15}$ clinical trials, ${ }^{16}$ public health surveys, ${ }^{17}$ and economic analysis, ${ }^{18}$ as well as needs assess- ment in genetics education. ${ }^{19}$ \\ THE EVIDENTIARY FOUNDATION FOR PUBLIC HEALTH GENOMICS}

With the rapid proliferation of genetic tests available for research and clinical practice as well as for direct-to-consumer personal genetic tests, it is important to have a strong evidentiary foundation for the role of genomics in improving population health. The National Institutes of Health Genetic Testing Registry ${ }^{20}$ currently contains information on more than 50,000 genetic tests conducted in nearly 500 laboratories, for more than 10,000 disease conditions, involving more than 16,000 genes. These tests cover numerous rare and common diseases and a variety of applications (e.g., risk assessment, predictive, diagnostic, and prognostic). Several advisory groups (e.g., the Task Force on Genetic Testing ${ }^{21}$ and the Secretary's Advisory Committee on Genetic Testing ${ }^{22}$ ) have made recommendations to strengthen the evidence base for genomics. Such groups established the need to collect clinical and population data to answer questions relevant to the intended use of these tests. The questions aim to determine the analytical validity of tests (showing the ability of tests to be accurate), their clinical validity (showing an association with disease end points), and their clinical utility (showing effectiveness in improving health outcomes). These questions have been explored in more depth by the ACCE (analytical validity, clinical validity, clinical utility, and ethical, legal, and social issues) framework. ${ }^{23}$

More recently, the National Academy of Sciences, Engineering, and Medicine released a report by a special committee that sought to "develop a framework for decision making regarding the use of genetic tests in clinical care." 24 The committee addressed medical applications and utility of genetic tests and examined how evidence is generated, evaluated, and integrated. It also reviewed several available evaluation methods, including $\mathrm{ACCE}^{23}$ and the EGAPP Working Group's approach to evaluation. ${ }^{9}$ The committee developed an updated evaluation process for decision making by policy makers and providers that incorporates elements of ACCE, EGAPP, and other evaluation methods. ${ }^{24}$
Table 3 CDC evidence-based classification of genetic and genomic tests and selected examples

\begin{tabular}{|c|c|c|}
\hline Tier & Evidence for recommendation & Examples \\
\hline $\begin{array}{l}\text { Tier } \\
1\end{array}$ & $\begin{array}{l}\text { Supported by a base of synthesized } \\
\text { evidence for implementation in practice }\end{array}$ & $\begin{array}{l}\text { HBOC, Lynch syndrome, } \\
\text { newborn screening, FH }\end{array}$ \\
\hline $\begin{array}{l}\text { Tier } \\
2\end{array}$ & $\begin{array}{l}\text { Synthesized evidence is insufficient to } \\
\text { support routine implementation in } \\
\text { practice; may provide information for } \\
\text { informed decision making }\end{array}$ & $\begin{array}{l}\text { Many } \\
\text { pharmacogenomics tests }\end{array}$ \\
\hline $\begin{array}{l}\text { Tier } \\
3\end{array}$ & $\begin{array}{l}\text { Evidence-based recommendation } \\
\text { against use; or irrelevant synthesized } \\
\text { evidence identified; not ready for } \\
\text { routine implementation in practice }\end{array}$ & $\begin{array}{l}\text { Direct-to-consumer } \\
\text { personal genetic tests }\end{array}$ \\
\hline
\end{tabular}

CDC, Centers for Disease Control and Prevention; FH, familial hypercholesterolemia; HBOC, hereditary breast and ovarian cancer.

\section{PRIORITIZING PUBLIC HEALTH ACTION BY LEVEL OF EVIDENCE AND HEALTH IMPACT}

Using the best available evidence to support clinical and public health action is always desirable, even in the face of rapidly changing information. To help prioritize genomic tests and applications for action, the CDC developed a relatively simple horizon-scanning method based on a threetier classification system (Table 3): 25,26

- Tier 1 genomic applications have synthesized evidence with an evidence-based guideline that supports implementation in clinical practice.

- Tier 2 genomic applications have insufficient evidence to support implementation in routine clinical practice. The evidence may provide information for informed decision making by individuals, clinicians, and policy makers.

- Tier 3 applications have either (i) synthesized evidence that supports recommendations against use or (ii) insufficient available evidence.

\section{EXAMPLES OF CURRENT PRIORITIES AND ACTIV- ITIES IN PUBLIC HEALTH GENOMICS}

The following are examples of current priorities and activities in public health genomics, including cancer, heart disease, newborn screening for rare diseases, and pathogen genomics.

\section{Hereditary cancers}

Two cancer genetic syndromes with tier 1 evidence-based applications-hereditary breast and ovarian cancer (HBOC) and Lynch syndrome-have been the focus of public health action at the federal and state levels. ${ }^{27}$ It is estimated that between 1 and 2 million people in the United States have one of these conditions, and most do not know it. HBOC most commonly involves mutations in BRCA1 and BRCA2 genes. About one in 500 women has a $B R C A$ mutation; they have a markedly increased risk for breast, ovarian, and other cancers. $B R C A$ mutations account for about $3 \%$ of breast cancers and $10 \%$ of ovarian cancers. ${ }^{27}$ Family health history can be used to 
identify those at increased risk, including a history of breast cancer before age 50, triple-negative breast cancer, ovarian cancer, cancer in both breasts, breast cancer in a male relative, or breast, pancreatic, or high-grade prostate cancer in multiple relatives. ${ }^{27}$ Lynch syndrome is associated with an increased risk for colorectal, endometrial, ovarian, and other cancers and is caused by mutations in DNA mismatch repair genes. ${ }^{27}$ Lynch syndrome accounts for $1-3 \%$ of colorectal cancer cases. ${ }^{26}$

For both HBOC and Lynch syndrome, evidence-based guidelines exist to reduce the burden of cancer in affected persons and their relatives. These guidelines have not been optimally implemented in the population, leading to disparities in use and health impact. For HBOC, the US Preventive Services Task Force recommends that primary care providers screen women to identify a family history that may suggest HBOC. ${ }^{28}$ High-risk women should be referred for genetic counseling and possible testing for BRCA mutations. Possible interventions for those found to have mutations include starting breast cancer screening earlier with mammography, chemoprevention medications, or risk-reducing surgery. For Lynch syndrome, the EGAPP Working Group recommends that all newly diagnosed colorectal cancer patients be offered testing for Lynch syndrome in order to identify a causal mutation for which close relatives could be tested to reduce their risk of morbidity and premature mortality. ${ }^{29}$ Patients with Lynch syndrome should be screened for colorectal cancer beginning at an earlier age and more frequently than the general population.

The CDC focuses on translating and implementing these recommendations into action. CDC activities include surveillance, epidemiologic research, communication, and partnerships. The agency has developed resources for patients and providers using the Know:BRCA clinical decision support tool $^{30}$ and the Bring Your Brave campaign. ${ }^{31}$ The Know: BRCA tool can help women and providers evaluate risk for $B R C A$ mutations. Bring Your Brave is a public health campaign that seeks to increase awareness of breast cancer in young women. The campaign materials include information on HBOC, genetic counseling, and genetic testing.

Several state public health departments are strengthening their capacity for cancer genomics activities, including public and provider education, monitoring the population burden of hereditary cancers, and improving access to care and services. For example, the Michigan Department of Health and Human Services has worked to reduce morbidity and mortality associated with hereditary cancers by improving genetic literacy, enhancing communication between patients and providers, and improving use of cancer risk assessment and genetic services. As an example, the Michigan program has collaborated with many partners to develop a free online continuing medical-education course. ${ }^{27}$ The number of persons receiving $B R C A$ counseling and testing in Michigan has increased steadily since 2008 . The Michigan program has also worked with health-insurance providers to promote coverage that is consistent with evidence-based guidelines. In
2009, only 4 of 25 health plans in the state had coverage policies consistent with guidelines. In 2016, 16 health plans provided coverage to approximately 8 million people. ${ }^{27}$

More recently, the National Cancer Moonshot Initiative's Blue Ribbon Panel made a recommendation to enhance national implementation and to study approaches to identifying and caring for individuals and families with inherited cancer syndromes. ${ }^{32}$ The National Cancer Institute held a workshop in 2017 that focused on implementation of Lynch syndrome screening. ${ }^{33}$ In 2017, the National Cancer Institute released a call for proposals to develop and test methods to improve ascertainment and delivery of evidence-based preventive and treatment services for hereditary cancer syndromes, ${ }^{34}$ develop sustainable approaches in diverse health-care settings and populations, and establish demonstration metrics for successful implementation, including interpretation of genetic testing.

\section{Familial hypercholesterolemia}

Familial hypercholesterolemia (FH) is a dominant genetic disorder that affects more than 1 million people in the United States. FH is characterized by elevated low-density lipoprotein cholesterol levels. ${ }^{35}$ Persons with FH have a markedly greater risk of heart disease, but when it is diagnosed and treated early in life, the risk is reduced by $\sim 80 \%{ }^{35}$ Active FH case finding followed by family-based cascade screening using cholesterol testing with or without DNA analysis has been recommended by several evidence groups. ${ }^{35}$

One major barrier to cascade screening for $\mathrm{FH}$ is the challenge of identifying the first case in a family (i.e., the proband). Current estimates suggest that fewer than $10 \%$ of $\mathrm{FH}$ cases in the United States have been identified. ${ }^{35} \mathrm{~A}$ recent study from the United Kingdom demonstrated the efficacy of screening children for $\mathrm{FH}$ during routine immunization visits at 1-2 years of age with elevated cholesterol levels as the criteria, in combination with genetic testing and repeat lipid testing. For every 1,000 children screened, 8 individuals with FH were identified: 4 children and 4 parents. ${ }^{36}$ Another potential strategy for index-case identification utilizes machine-learning techniques to mine electronic healthrecord data, laboratory data, and billing-code data to flag individuals with characteristics consistent with $\mathrm{FH}$ for formal identification by a physician. ${ }^{37}$ Finally, a recent study ${ }^{38}$ reported that large-scale DNA sequencing was effective in identifying carriers of FH variants, few of whom had been diagnosed clinically.

\section{Rare diseases and newborn screening}

In the United States, a rare disease is defined as a condition that affects fewer than 200,000 people. ${ }^{39}$ Although individually rare, collectively, rare diseases affect about 25 million people. ${ }^{39}$ They can have severe health impacts on patients and families, including physical and intellectual disabilities as well as premature death. Also, the economic impact of rare diseases is substantial for patients, families, and society. ${ }^{39}$ 
Newborn screening is the best-known public health response to certain rare diseases. ${ }^{40}$ As an organized public health program in all states, newborn screening started in the United States more than five decades ago with testing for phenylketonuria. ${ }^{40}$ Today, newborn screening is a complex public health system that involves diagnosis, treatments, follow-up, and evaluation. Testing is now recommended for more than 30 genetic, metabolic, and other disorders, using either dried blood spots or other clinical point-of-care tests. ${ }^{41}$ Most newborn screening tests for genetic diseases are biochemical tests. Tandem mass spectrometry makes it possible to screen for many conditions simultaneously; this has led to a huge expansion in the number of conditions that could be included. Currently, next-generation sequencing in newborn screening is not recommended as a first-tier test but is being explored in research studies as a follow-up secondary test. $^{42,43} \mathrm{~A}$ few clinical research studies are exploring the use of genome sequencing in newborns to explore the potential benefits and harms as well as to evaluate associated ethical, legal, and social implications (e.g., ref. 44).

Beyond newborn screening, whole-genome and -exome sequencing of patients and their relatives has accelerated discovery of the genomic basis for an increasing number of rare diseases. ${ }^{45}$ To date, underlying molecular genetic causes have been found for more than 4,000 Mendelian conditions. Recent data show an increase in diagnostic yield of wholegenome or -exome sequencing as a first test for conditions suspected to be genetic, thus shortening the delay in definitive diagnosis and appropriate treatment that many families experience, referred to as the diagnostic odyssey. ${ }^{46,47}$ Standardized codes in clinical records, hospital databases, and other records that incorporate diagnostic testing might be used in the future to track with more precision the burden, natural history, and impact of interventions for rare diseases. ${ }^{39}$

A recently proposed framework for a public health response to rare diseases ${ }^{40}$ contains nine elements with five overarching components (similar to the essential public health functions described above): (i) assessment of disease burden-e.g., numbers of affected individuals, health outcomes, health-care use, and costs; (ii) research into causes and treatments; (iii) systems for early identification; (iv) education of patients, families, and providers; and (v) public policies to promote access to services and treatments.

\section{Role of pathogen genomics in infectious-disease control and prevention}

Perhaps the most fully realized application of public health genomics so far is in infectious diseases, where advances in pathogen genomics are already changing both medical and public health practice. ${ }^{48}$ Pathogen genomics and bioinformatics have transformed public health laboratory surveillance, which provides data for monitoring trends, detecting outbreaks, and conducting public health investigations and response to infectious-disease outbreaks. New methods are also enhancing the development of clinical diagnostics and vaccines. ${ }^{48}$ In the past, surveillance systems have relied on clinical laboratories to identify pathogens from patient isolates, report results, or send isolates to health-department laboratories for additional characterization that took hours to days of work. Today, sequencing is starting to replace traditional microbiology techniques. These faster and more accurate methods can help public health personnel recognize and stop outbreaks earlier, preventing illness and saving lives. $^{48}$

In 2014, the CDC launched the Advanced Molecular Detection and Response to Infectious Disease Outbreaks initiative to allow integration of sequencing and bioinformatics with traditional epidemiology in infectious-disease control. ${ }^{49} \mathrm{~A}$ recent article reviewed the program and its goals and priorities, and described examples of early successes. ${ }^{48} \mathrm{~A}$ leading application of genome-sequencing methods is in detecting and controlling foodborne outbreaks. Millions of people in the United States are affected by foodborne illnesses, resulting in more than 100,000 hospitalizations and 3,000 deaths each year. Most cases are not associated with recognized outbreaks, although more than 1,000 outbreaks are investigated annually. ${ }^{48} \mathrm{~A}$ collaborative nationwide Listeria whole-genome sequencing project demonstrated that sequencing was effective in identifying more clusters, attributing them to specific sources. ${ }^{48}$ The results also showed that outbreak clusters are caught earlier, potentially preventing severe illnesses and deaths. Other examples of early success include enhancing the development of seasonal influenza vaccines, improving contact investigations in HIV clusters, detecting emerging infections, and combating antimicrobial resistance. ${ }^{48}$

\section{LOOKING AHEAD: GENOMICS, PRECISION MED- ICINE, AND PRECISION PUBLIC HEALTH}

In many ways, genomics has served as the foundation for "precision medicine." However, precision medicine is much more than genomic medicine. It focuses on individual differences in genes, environment, and lifestyle, allowing the design of targeted disease interventions (treatment and prevention). The US Precision Medicine Initiative, launched in $2015,{ }^{50}$ promises a new era of biomedical research and health care. The initiative is enabled by rapid advances in biomedical sciences, including bioinformatics, information technologies, and data science. A national cohort of at least 1 million people ${ }^{51}$ will be enrolled through the National Institutes of Health's AllofUs Research Program to evaluate genetic and environmental determinants of various diseases. This initiative will require a public health perspective and partnership to help ensure generalizability to the population, focus on preventive interventions, and increase the efficiency and precision with which interventions are implemented..$^{52}$

For example, implementing tier 1 genomic applications in the million-person cohort could provide benefits to the study participants and their families. The cohort will be expected to include thousands of patients with HBOC, Lynch syndrome, and FH. These individuals and their relatives could help 
evaluate best individual and system-wide implementation strategies to reduce risk. Other potential targets may include a selected subset of highly actionable genes that the American College of Medical Genetics and Genomics ${ }^{53}$ has recommended be analyzed when individuals undergo genome sequencing. In addition, tier 2 genomic applications, including many pharmacogenomic traits, could be explored, not only for their associations with drug-related health benefits and adverse effects (clinical validity), but also for their ability to improve health outcomes using clinical trials and observational studies.

The same technologies used in precision medicine are also ushering in a new era of "precision public health" 54 that can improve our ability to provide the right health intervention to the right population at the right time. Precision public health involves the collection of more accurate population- and individual-level data on genes, exposures, behaviors, and other social/economic health determinants; enhancing public health action for improving health in subpopulations in need of recommended prevention measures; and addressing and reducing health disparities in the population by using more precision data for action.

As described above, the use of human and pathogen genomics technologies in public health efforts has already contributed to the inception of precision public health. ${ }^{54}$ In addition to genomics, precision public health can include the use of mobile technologies to track health and disease and geographic analysis to measure social and environmental determinants of health. ${ }^{54}$ In fact, the scope of precision public health goes well beyond genomics and includes careful evaluation of the interaction between biological and environmental/social determinants of health. As discussed by Dowell et al..$^{55}$ in the context of child mortality in Africa, the path to precision public health includes enhanced population surveillance, laboratory investigations, and training-all crucial in delivering the right intervention to the right subpopulation at the right time.

Beyond outbreak investigations, pathogen genomics has the potential to clarify relationships between infectious diseases and chronic illnesses. In particular, investigations of the human microbiome seem to be promising in assessing the role of infectious diseases in a wide variety of diseases, including obesity and diabetes. ${ }^{56}$ In the short run, the CDC and other public health agencies are investigating the role of the microbiome in antimicrobial resistance, an increasingly important public health priority. ${ }^{57}$

Even after 20 years of public health genomics, skepticism in the public health community about its role in improving population health remains high. ${ }^{58}$ Certainly, the hype about the potential role of the new technologies in improving the health of communities and reducing health disparities may have contributed to this disenchantment. ${ }^{58}$ Genomics is only one approach to improving health, and for the most part cannot be used in isolation from other factors or determinants of health and disparities including socioeconomic factors such as housing, education, and access to care. The aspects described in this report represent only the early impacts of this field on population health. Finally, there remain major scientific, legal, and ethical challenges in the use of genome sequencing as a screening tool for improving population health. Certainly, there is a potential for population screening in adults for selected high-penetrant genes to reduce the burden of cancer, heart disease, and other conditions, but careful investigation is needed before its implementation. ${ }^{59}$

In conclusion, there is a path forward using evidence-based approaches to implement genome-based technologies in practice. A major challenge for the emerging field of precision public health will be to determine how to best use large-scale data, including genomic and environmental information, in order to better understand determinants of population health and target interventions that can improve health outcomes in subpopulations. ${ }^{58}$ Ultimately, improving population health will require a combination of interventions targeted at whole populations (e.g., access to care, nutrition, and education) and those tailored to high-risk groups (based on genetics and/or other factors) in order to prevent disease, improve health care, and reduce health disparities.

\section{ACKNOWLEDGMENTS}

The authors thank Scott Grosse for providing valuable comments on an earlier version of this paper. The findings and conclusions in this report are those of the authors and do not necessarily reflect the position of the Centers for Disease Control and Prevention.

\section{DISCLOSURE}

The authors declare no conflict of interest.

\section{REFERENCES}

1. Khoury MJ, Burke W, Thompson E. Genetics and Public Health in the 21st Century: Using Genetic Information to Improve Health and Prevent Disease. Oxford University Press: New York, 2000.

2. Khoury MJ. Public health genomics: the end of the beginning. Genet Med 2011;13:206-9.

3. Khoury MJ, Coates RJ, Fennell ML, et al. MLI Multilevel research and the challenges of implementing genomic medicine. J Natl Cancer Inst Monogr 2012:112-120.

4. Institute of Medicine: The Future of Public Health. National Academy Press: Washington, DC, 1988.

5. Association for State and Territorial Health Officials. 2010 State Public Health Genomics Resource Guide. http://www.astho.org/Programs/ Access/Genomics/The-2010-State-Public-Health-Genomics-ResourceGuide/. Accessed 1 January 2011.

6. Beskow LM, Khoury MJ, Baker T, Thrasher JF. The integration of genomics into public health research, policy and practice in the United States. Community Genet 2001;4:2-11.

7. Khoury MJ, Bowen MS, Burke W, et al. Current priorities for public health practice in addressing the role of human genomics in improving population health. Am J Prev Med. 2011;40:486-93.

8. Kemper AR, Green NS, Calonge N, et al. Decision-making process for conditions nominated to the recommended uniform screening panel: statement of the US Department of Health and Human Services Secretary's Advisory Committee on Heritable Disorders in Newborns and Children. Genet Med 2014;16:183-187.

9. Teutsch SM, Bradley LA, Palomaki GE, et al. The Evaluation of Genomic Applications in Practice and Prevention (EGAPP) Initiative: methods of the EGAPP Working Group. Genet Med 2009;11:3-14.

10. Bellcross CA, Bedrosian SR, Daniels E, et al. Implementing screening for Lynch syndrome among patients with newly diagnosed colorectal cancer: summary of a public health/clinical collaborative meeting. Genet Med. 2012;14:152-162. 
11. Deverka PA, Schully SD, Ishibe N, et al. Stakeholder assessment of the evidence for cancer genomic tests: insights from three case studies. Genet Med 2012;14:656-662.

12. Sahai I, Eaton RB, Hale JE, et al. Long-term follow-up to ensure quality care of individuals diagnosed with newborn screening conditions: early experience in New England. Genet Med. 2010;12(12 suppl):S220-7

13. Wiesman $C$, Rose $E$, Grant A, et al. Experiences from a pilot program bringing BRCA1/2 genetic screening to the US Ashkenazi Jewish population. Genet Med 2017;19:529-536.

14. Scheuner MT, Peredo J, Tangney K, et al. Electronic health record interventions at the point of care improve documentation of care processes and decrease orders for genetic tests commonly ordered by nongeneticists. Genet Med 2017;19:112-120.

15. Lynch JA, Berse B, Dotson WD, et al. Utilization of genetic tests: analysis of gene-specific billing in Medicare claims data. Genet Med. 2017;19: 890-899.

16. Rubinstein WS, Acheson LS, O'Neill SM, et al. Clinical utility of family history for cancer screening and referral in primary care: a report from the Family Healthware Impact Trial. Genet Med 2011;13:956-965.

17. Kolor K, Duquette D, Zlot A, et al. Public awareness and use of direct-toconsumer personal genomic tests from four state population-based surveys, and implications for clinical and public health practice. Genet Med. 2012;14:860-867

18. D'Andrea E, Marzuillo C, DeVito C, et al. Which BRCA genetic testing programs are ready for implementation in health care?: a systematic review of economic evaluations. Genet Med 2016;18:1171-1180.

19. Plunkett-Rondeau J, Hyland K, Dasgupta S. Training future physicians in the era of genomic medicine: trends in undergraduate medical genetics education. Genet Med. 2015;17:927-934.

20. Rubinstein WS, Maglott DR, Lee JM, et al. The NIH genetic testing registry: a new, centralized database of genetic tests to enable access to comprehensive information and improve transparency. Nucleic Acids Res. 2013;41(Database issue):D925-35.

21. Task Force on Genetic Testing, National Institutes of Health, Department of Energy Working Group on Ethical, Legal and Social Implications of Human Genome Research. Promoting safe and effective genetic testing in the United States. September 1997. https://www.genome.gov/ 10001733/. Accessed 3 August 202017.

22. Secretary's Advisory Committee on Genetic Testing. Enhancing the oversight of genetic tests: recommendations of the SACGT. July 2000. https://osp.od.nih.gov/wp-content/uploads/2013/11/oversight_report. pdf. Accessed 3 August 2017.

23. Centers for Disease Control and Prevention. ACCE model process for evaluating genetic tests. Accessed 3 August 2017. https://www.cdc.gov/ genomics/gtesting/acce/index.htm.

24. Committee on the Evidence Base for Genetic Testing, National Academies of Sciences, Engineering, and Medicine. An evidence framework for genetic testing. 27 March 2017. http:// nationalacademies.org/hmd/Reports/2017/an-evidence-framework-forgenetic-testing.aspx. Accessed 3 August 2017.

25. Dotson WD, Douglas MP, Kolor, et al. Prioritizing genomic applications for action by level of evidence: a horizon-scanning method. Clin Pharmacol Ther 2014;95:394-402.

26. Centers for Disease Control and Prevention. Public Health Genomics Knowledge Base, Tier table. Accessed 3 August 2017. https://phgkb.cdc. gov/PHGKB/topicStartPage.action.

27. Rodriguez JL, Thomas CC, Massetti GM, et al. CDC grand rounds: family history and genomics as tools for cancer prevention and control. MMWR Morb Mortal Wkly Rep. 2016;65:1291-1294.

28. Moyer VA; US Preventive Services Task Force. Medications for risk reduction of primary breast cancer in women: US Preventive Services Task Force recommendation statement. Ann Intern Med 2013;159: 698-708.

29. Evaluation of Genomic Applications in Practice and Prevention (EGAPP) Working Group. Recommendations from the EGAPP Working Group: genetic testing strategies in newly diagnosed individuals with colorectal cancer aimed at reducing morbidity and mortality from Lynch syndrome in relatives. Genet Med 2009;11:35-41.

30. Centers for Disease Control and Prevention. Know: BRCA tool for providers and the public. Accessed 3 August 2017. https://www.cdc.gov/ cancer/breast/young_women/knowbrca.htm.

31. Centers for Disease Control and Prevention. Bring Your Brave Campaign. Accessed 3 August 2017. https://www.cdc.gov/cancer/breast/young_ women/bringyourbrave/index.htm.
32. National Cancer Institute. Cancer Moonshot Blue Ribbon Panel report 2016. Accessed 3 August 2017. https://www.cancer.gov/research/keyinitiatives/moonshot-cancer-initiative/blue-ribbon-panel/blue-ribbon-panelreport-2016.pdf

33. National Cancer Institute. Approaches to Blue Ribbon Panel recommendations: the case of Lynch syndrome. 2017. Accessed 3 August 2017. https://cancercontrol.cancer.gov/lynch-syndrome-workshop/

34. National Cancer Institute. Upcoming Cancer Moonshot funding opportunities. Accessed 3 August 2017. https://www.cancer.gov/ research/key-initiatives/moonshot-cancer-initiative/funding/upcoming

35. Knowles JW, Rader DJ, Khoury MJ. Cascade screening for familial hypercholesterolemia and the use of genetic testing. JAMA. 2017;318: 381-382.

36. Wald DS, Bestwick JP, Morris JK, et al. Child-parent familial hypercholesterolemia screening in primary care. N Engl J Med. 2016;375: 1628-1637.

37. Safarova MS, Liu H, Kullo IJ. Rapid identification of familial hypercholesterolemia from electronic health records. J Clin Lipidol. 2016;10:1230-1239.

38. Abul-Husn NS, Manickam K, Jones LK, et al. Genetic identification of familial hypercholesterolemia within a single U.S. health care system. Science 2016;354:aaf7000

39. Valdez R, Grosse SD, Khoury MJ. The need for a next-generation public health response to rare diseases. Genet Med 2016;19:489-490.

40. Boyle CA, Bocchini Jr JA, Kelly J. Reflections on 50 years of newborn screening. Pediatrics 2014 Jun;133:961-963.

41. Newborn Screening Clearinghouse. Baby's first test: conditions screened by state. Accessed 3 August 2017. http://www.babysfirsttest.org/ newborn-screening/states

42. Berg JS, Agrawal PB, Bailey DB, et al. Newborn sequencing in genomic medicine and public health. Pediatrics 2017;139:e20162252.

43. Ceyhan-Birsoy O, Machini K, Lebo MS, et al. A curated gene list for reporting results of newborn genomic sequencing. Genet Med. 2017;19: 809-818.

44. Danielsson K, Mun LJ, Lodermann A, et al. Next-generation sequencing applied to rare diseases genomics. Expert Rev Mol Diagn 2014;14: 469-487.

45. Baynam G, Pachter N, McKenzie F, et al. The rare and undiagnosed diseases diagnostic service - application of massively parallel sequencing in a state-wide clinical service. Orphanet J Rare Dis 2016;11:77.

46. Lemke JR. High-throughput sequencing as first-tier diagnostics in congenital and early-onset disorders. JAMA Pediatr 2017;171: 833-835.

47. Richards $C L$, lademarco MF, Atkinson D, et al. Advances in public health surveillance and information dissemination at the centers for disease control and prevention. Public Health Rep 2017;132:403-410.

48. Gwinn M, MacCannell DR, Khabbaz RF. Integrating advanced molecular detection technologies into public health. J Clin Microbiol 2017;55: 703-714.

49. Centers for Disease Control and Prevention. Advanced Molecular Detection Initiative. Accessed 3 August 2017. https://www.cdc.gov/ amd/

50. Collins FS, Varmus H. A new initiative on precision medicine. N Engl J Med 2015;372:793-795.

51. National Institutes of Health. AllofUs Research Program. Accessed 3 August 2017. https://allofus.nih.gov/

52. Khoury MJ, Evans JP. A public health perspective on a national precision medicine cohort: balancing long-term knowledge generation with early health benefit. JAMA 2015;313:2117-2118.

53. Kalia SS, Adelman K, Bale SJ, et al. Recommendations for reporting of secondary findings in clinical exome and genome sequencing, 2016 update (ACMG SF v2.0): a policy statement of the American College of Medical Genetics and Genomics. Genet Med 2017;19: 249-255.

54. Khoury MJ, lademarco MF, Wiley WT. Precision public health for the era of precision medicine. Am J Prev Med 2016; 50:398-401.

55. Dowell SF, Blazes D, Desmond-Hellman S. Four steps to precision public health. Nature 2016;540:189-191.

56. Blum HE. The human microbiome. Adv Med Sci 2017;62:414-420.

57. Laufer Halpin A. Precision public health: harnessing the power of the microbiome. CDC blog post, 2016. Accessed 14 October 2015. https:// blogs.cdc.gov/genomics/2017/06/07/precision-public-health/

58. Khoury MJ, Galea S. Will precision medicine improve population health? JAMA. 2016;316:1357-1358. 
59. Evans JS, Berg JS, Olshan AF, et al. We screen newborns, don't we? Realizing the promise of public health genomics. Genet Med. 2013;15: 332-334.

60. Centers for Disease Control and Prevention. Genomics and Health Impact weekly update. Accessed 3 August 2017. https://www.cdc.gov/ genomics/update/current.htm

61. Centers for Disease Control and Prevention. The Human Genome Epidemiology Navigator. Accessed 3 August 2017. https://phgkb.cdc. gov/PHGKB/hNHome.action

62. Centers for Disease Control and Prevention. Genomic Workforce Competencies. Accessed 3 August 2017. https://www.cdc.gov/ genomics/translation/competencies/index.htm

63. Centers for Disease Control and Prevention. University Centers for Genomics and Public Health. Accessed 3 August 2017. https://www.cdc. gov/genomics/translation/centers.htm

64. Centers for Disease Control and Prevention. Family History Public Health Initiative. Accessed 3 August 2017. https://www.cdc.gov/genomics/ famhistory/campaign.htm

65. St Pierre J, Bach J, Duquette D, et al. Strategies, actions, and outcomes of pilot state programs in public health genomics, 2003-2008. Prev Chron Dis. 2014;11:E97.

66. EGAPP Working Group. The EGAPP initiative: lessons learned. Genet Med; 2014;16:217-224

67. Burke W, Khoury MJ, Stewart A, et al. The path from genome-based research to population health: development of an international public health genomics network. Genet Med 2006;8:451-458.

68. Khoury MJ, McBride CM, Schully SD, et al. The scientific foundation for personal genomics: recommendations from a National Institutes of Health-Centers for Disease Control and Prevention multidisciplinary workshop. Genet Med 2009;11:559-567.
69. McBride CM, Bowen SM, Schully SD, Khoury MJ. Introduction to the 4th National Conference on Genomics and Public Health. Public Health Genomics 2012;15:117.

70. Trivers KF, Rodriguez JL, Cox SL, et al. The activities and impact of state programs to address hereditary breast and ovarian cancer, 2011-2014. Healthcare (Basel) 2015;3:948-963.

71. Bowen S, Kolor K, Dotson WD, et al. Public health action in genomics is now needed beyond newborn screening. Public Health Genomics. 2012;15:327-334.

72. Dotson WD, Douglas MP, Kolor K, et al. Prioritizing genomic applications for action by level of evidence: a horizon-scanning method. Clin Pharmacol Ther 2014;95:394-402.

73. Yu W, Gwinn M, Dotson WD, et al. A knowledge base for tracking the impact of genomics on population health. Genet Med 2016;18:1312-1314.

74. Roberts MC, Kennedy A, Chambers DA, et al. The current state of implementation science in genomic medicine: opportunities for improvement. Genet Med 2017;19:858-863

75. Philips KA, Deverka PA, Sox HC, et al. Making genomic medicine evidence based and patient-centered: a structured review and landscape analysis of comparative effectiveness research. Genet Med 2017;19: 1081-1091

76. Schully SD, Lam TK, Dotson WD et al. Evidence synthesis and guideline development in genomic medicine: current status and future prospects. Genet Med. 2015;17:63-67.

77. Hunter JE, Irving SA, Biesecker LG, et al. A standardized, evidence-based protocol to assess clinical actionability of genetic disorders associated with genomic variation. Genet Med 2016;18:1258-1268.

78. Tan TY, Dilan OJ, Stark Z. Diagnostic impact and cost-effectiveness of whole-exome sequencing for ambulant children with suspected monogenic conditions. JAMA Pediatrics 2017;171:855-862 